\title{
A Census of Premenstrual Syndrome in Young Adolescent Girls: Facts about Women Health in Developing Country
}

Tamseela Mumtaz $^{1^{*}}$, Nabila Roohi $^{2}$ and Muhammad Amir Iqbal ${ }^{2}$

${ }^{1}$ GC Women University, Faisalabad, Punjab, Pakistan

2 University of the Punjab, Lahore, Pakistan

*Corresponding author: Tamseela Mumtaz, 1GC Women University, Faisalabad, Punjab, Pakistan, Tel: +923324474630; E-mail: gr8zoologist@gmail.com

Received Date: Apr 14, 2018; Accepted Date: May 29, 2018; Published Date: Jun 06, 2018

Copyright: ( 2018 Mumtaz T, et al. This is an open-access article distributed under the terms of the Creative Commons Attribution License, which permits unrestricted use, distribution, and reproduction in any medium, provided the original author and source are credited.

\begin{abstract}
Introduction: Women often experienced ragged and unpredicted kind of behavior and hardly recognize their attitude as premenstrual syndrome. Adolescent girls are particularly naïve and unacquainted of the symptoms and if aware, hide due to shyness.
\end{abstract}

Method: In this cross sectional study, a survey was conducted in educational institutes to determine the prevalence of various categories of PMS in young teen agers girls at different stages of their luteal phase. Predominance of PMS was finding out by applying Chi square test and significant incidences of PMS was observed.

Result: PMS-A is recognized as a recurring phenomenon with most number of victims. Mild anxiety experienced by $38 \%$ respondents and severe mood swings affected more than $22 \%$ college going girls. PMS-H vie PMS-A having maximum numbers of females with complain of spartan type of fluid retention. Abdominal bloating and breast tenderness found as customary signs and $70 \%$ pubescent girls face these troubles before and during menstruation. Depression crying and fatigue are other major warning cryptograms of PMS.

Conclusion: Frequency of premenstrual syndrome must be figure out in adolescent girls and they must educate about its indications, complications and outcomes to ensure the good quality of women health at their reproductive age.

Keywords: Premenstrual syndrome; Women health; PMS categories

\section{Introduction}

Young girls embraced many physical changes for attainment of adulthood. At luteal stage of their reproductive cycle, many indications accomplish the criteria of premenstrual syndrome but scarcely concede as premenstrual syndrome. Premenstrual syndrome (PMS) refers to physical and emotional symptoms that occur in the one to two weeks before a woman's period. It is a persistent luteal-phase condition characterized by physical, psychological, and behavioral changes of ample severity leading to deterioration of interpersonal relationships and normal routine activity. The definite cause of PMS is still unclear but some nutritional factors like amino acids, calcium, magnesium and vitamin B deficiency may be a possible reason of PMS development [1-3]. Involvement of ovarian hormones can also be not neglected as the fluctuations in these sex hormones before menstruation leads to mood swings and depression. The estrogen has excitatory effect on brain whereas progesterone activate inhibitory neurotransmitters and calm down the nervous system, therefore, fall of estrogen and raise in progesterone during luteal phase affect the brain excitatory and inhibitory system resulting in low mood and depression [4]. Many neurotransmitters such as serotonin and GABA are seemed to play roles in PMS. Serotonin, an excitatory neurotransmitter, is considered as a mood stabilizer and its concentration found to be decreased, whereas, increased production of inhibitory neurotransmitters such as GABA and endorphin may be noticed in women suffering from PMS.
The statistics about prevalence of premenstrual syndrome in Pakistani females is not known. Women usually brought up with the thinking that being a female, they should bear pain and other conditions associated with menstruation and must not complain about it. That's why most of the girls feeling insolent in revealing facts and reported PMS as normal. Moreover, self-medication is also a big hindrance in estimating the PMS, therefore no actual data is available about female suffering PMS in Pakistan. In an old study conducted in Karachi, the prevalence of PMS was 33\% [5]. Till now no complete statistics is recorded for PMS in Pakistani women. Different demographic studies are available and it is mandatory to gather all the data for a comprehensive account of the disease in the country. This study is designed to collect data from educated adolescent girls attending various institutes to rationalize the figures about PMS. The study targets major female university as well as other co-education organizations of Faisalabad, Punjab, Pakistan to report maximum numbers of female students suffering from PMS in the city.

Menstrual disorders are quite common in teen agers and most of the women experience remarkable variations at the age of 10-16 years. The existence of at least 5 indicators out of 11 symptoms mentioned for this syndrome is essential [6]. These symptoms are stress, anxiety, change of mood (feeling sad and crying all of a sudden), depressed mood, persistent anger or personal clashes, reduce interest in social relationships and work, feeling of immersion or being out of controls, change in appetite (over eating or having little appetite), difficulty in sleeping (oversleeping or insomnia), lack of concentration, fatigue and lethargy, and physical symptoms (chest pain, abdominal pain, joint or 
muscle pain, back pain, frequent urination, weight gain, acne, nausea abdominal bloating, chest sensitivity and headache) $[7,8]$. There is no specific laboratory test or physical exam is established for the diagnosis of PMS, however in a practice bulletin published in 2000, ACOG describe that PMS can be diagnosed if at least one of the effective and one of the somatic symptoms must be reported 5 days before the onset of menstruation in the consecutive three reproductive cycles [9].

\section{Material and Methods}

A cross sectional study was planned to find out the prevalence of PMS and its effects on emotional and physical health. The target population includes teen agers from local population attending colleges and universities. A total 500 girls were agreed to participate in the study willingly and voluntarily but 50 girls hide the information due to limitations imposed by family representing the conservative rational in the society, hence record of 450 girls is available for discussion. It was clarified to them that the study was only for collecting the data about severity and prevalence of premenstrual syndrome. A comprehensive questionnaire designed by Dr. Ricki Pollycove for PMS diagnosis was used to access the somatic and emotional variation during, before and after one week of menses. The questionnaire was subdivided into 5 categories. The PMS-A most common symptomatic category related to mental condition like anxiety, PMS-C related to feeding behavior such as craving, PMS-D and $\mathrm{H}$ linked with physical unease particularly depression and headache. Some other symptoms related to physical/facial appearance are also included in the questionnaire. These all categories are further segmented into mild, moderate and severe level to explore the severity of conditions. A liberal verbal explanation about the prospective and consequence of the survey was delivered to the participants and described information was recorded after obtaining informed consent. The descriptive statistical method was applied to calculate the frequency and percentage of different characteristics. Comparison between different variables at week before and after the periods was assessed through chi square test using Graph pad Prism (V6.0).

\section{Results and Discussion}

The volunteers of the study were 16-19 year old and mean age of 457 participants' is 16.5 . The study reveals that $92 \%$ young female population is somehow effected by PMS and only $8 \%$ girls denied any condition related to syndrome. Among various PMS categories, PMS$\mathrm{A}$ is more frequent in prevalence as majority of teen agers have complaint about various symptoms of PMS-A. Among these, 408 $(89.27 \%)$ young girls feel more anxiety during or before menstruation and have disturbed or restless routine life. Mild and moderate anxiety felt by $38 \%$ and $32 \%$ students, respectively, while $19 \%$ students presenting complaint of severe type of anxiety. Other than anxiety, large numbers of students $(383,83.8 \%)$ have complaints of mood swings. They feel their selves emotionally upset, ragged and often lose control on their nerves. According to them, sometimes, one week prior to menstruation, they became unpredictable and react in hostile manners. These mood swings found to be intense in $22 \%$ females though $28 \%$ females can handle this mood instability. Approximately, $33 \%$ students accept these attitude smacks and $16 \%$ participants totally denied any change in their temperaments. Similar trend was observed in nervous tension where reasonably less number of participants (17.5\%) was effecting from extreme strains and $34.8 \%$ have manageable stress. Volunteers of the study also developed impatience before or onset of menstruation. Among them, 21\% reported intense type of irritability whereas $30.4 \%$ and $28.7 \%$ complained tolerable and minor irascibility respectively. A statistical significant increase was noticed in prevalence of PMS-A $(\mathrm{P}=0.0006)$ as very little number of girls indicated no signs of anxiety, depression, mood swings and nervous tension $(10.72 \%, 20 \%, 16.2 \%$ and $19.25 \%$ respectively). In women with severe PMS, irritability and mood swings can become outbursts of anger and rage (Figure 1 and Table 1).

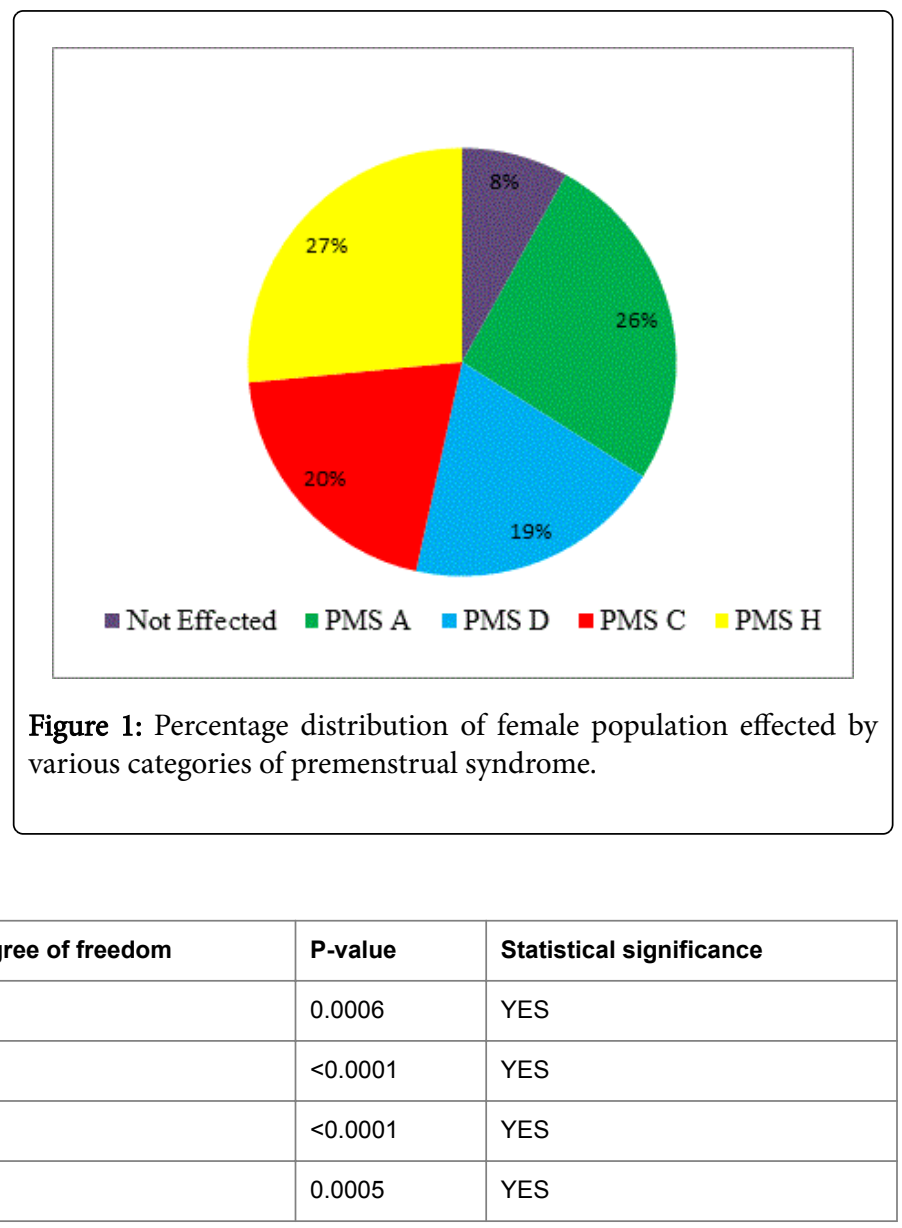

Table 1: Contingency analysis of various PMS categories by Chi-square.

The major symptom of PMS-D is depression caused by decrease level of peripheral estrogen due to increase level of A-MAO [10]. Almost $68.3 \%$ students undergo depression during or before PMS and among them $14 \%$ felt severe form of depression while $34.8 \%$ students suffered from mild depression. Crying is also a prominent signal of PMS and may be due to over secretion of prolactin. Significant higher 
level of prolactin was found between 15-30 years of age therefor teen agers and pubertal girls during their luteal phase are more tearful with repeated episodes of crying [11]. So the results was according to situation and $32.9 \%$ girls of higher secondary education complaint about moderate to severe emotional disturbance and approximate similar number of student admit mild crying during menstruation. Forgetfulness is also another problem in women suffering from PMS. Again, estrogen is the main culprit behind the scene as it controls the thinking part of the brain and the women with lack of estrogen have lapses of memory losses, though, once estrogen level recovered after menstruation, forgetfulness vanished. However, young girls are not too much affected by this estrogen decrease because $47.48 \%$ student did not have any complaint of amnesia. Only $28.22 \%$ suffered from slight absent mindedness. In luteal phase, majority of teenager developed complaint of misperception $(25.16 \%, 24.72 \%$ mild and moderate respectively) which reached to an extreme in $13 \%$ students. Menstruation and pre-menstruation leads to disturb sleep and $64.34 \%$ teen agers encounter with insomnia during these days while rest of girls have no change in sleep habit. PMS-D showed highly significant prevalence $(\mathrm{p}<0.0001)$ when compared to non-effected young population (Figure 2).

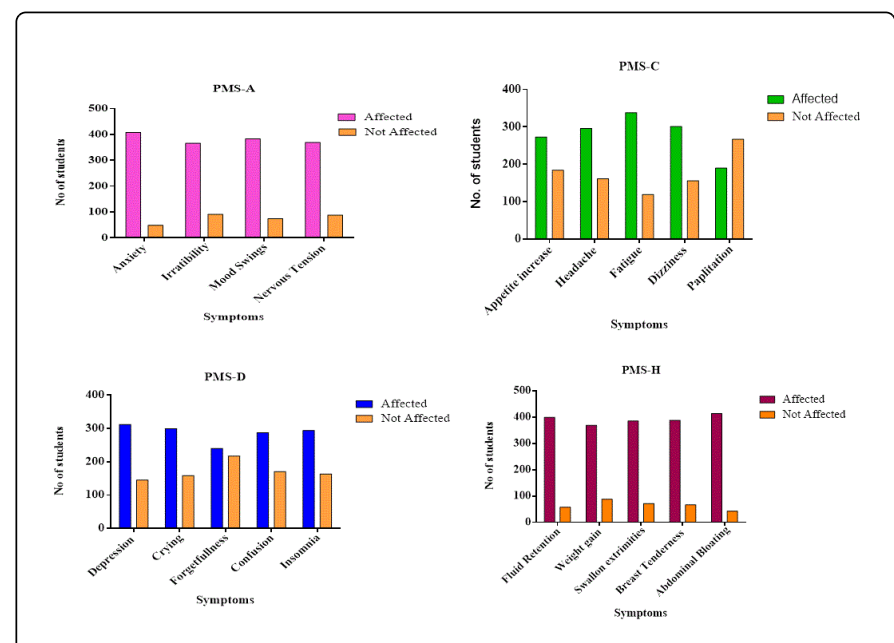

Figure 2: Assessments of various PMS Symptoms: PMS-A, PMS-C, PMS-D, PMS-H.

Somatic symptoms appeared due to decrease in estrogen level. These indicators include increase in appetite, headache, fatigue, dizziness and palpitations. One week prior to menstrual flow, intense desire of eating particular food was recognized by the participants [12]. In PMS-C, increased appetite affect $59.73 \%$ girls, out of these, $33.48 \%$ and $18.81 \%$ girls felt mild to moderate increase in appetite respectively, and $7.44 \%$ reported severe appetite while $40.27 \%$ feel no variation in appetite pattern. The reason of altered appetite habit may be attributed to chemical changes in brain resulting in inadequate level of serotonin and progesterone during premenstrual phase which leads to body dissatisfaction and develop desire of more eating, fatigue the muscles and sleeping problems. Complaints of headache, fatigue, dizziness and palpitations $(64.76 \%, 73.95 \%, 65.85 \%$ and $58.42 \%)$ are also noticed by study participants and pervasiveness establishes highly significant value $(\mathrm{P}<0.0001)$. Chemical ups and downs due to fluctuations of serotonin are thought to play a crucial role in triggering somatic PMS$\mathrm{C}$ symptoms. Insufficient amounts of serotonin may contribute to premenstrual depression, as well as to fatigue, food cravings and sleep problems. Serotonin assist in attitude, behavior and happiness regulation and have properties that protect against PMS-C, so a reduction in serotonin level may elucidate the somatic changes associated with premenstrual craving syndrome.

In women with premenstrual syndrome, negative changes start soon after ovulation, gradually increasing as the corpus luteum develops, and reached a maximum during the last 5 days of the luteal phase. These symptoms decline rapidly once menstruation starts, disappearing within one or two days of ovarian steroids reaching baseline levels. Fluid retention is significant symptom of PMS-H. Its mild, moderate and severe effect was felt by $27.13 \%, 34.13 \%$ and $26.03 \%$ girls respectively, while $12.7 \%$ girls have no complaint of fluid retention. Weight gain was observed in $80.73 \%$ teenagers prior to menstruation $(28.22 \%$ mild, $32.16 \%$ moderate and $20.35 \%$ has severe increase in weight) but $19.25 \%$ girls reported no change in weight due to PMS. Similarly mild breast tenderness is sensed in $84.9 \%$ young girls however $14.66 \%$ feel no tenderness. These symptoms may be associated with progesterone deficiency and estrogen dominance most notably fluid retention, breast swelling, headaches, loss of libido, and poor sleep patterns. Adolescent girls are diets conscious and eat very less resulting in less mineral and vitamin intake which may be a cause of PMS. Deficiencies in calcium and vitamin B (thiamine, riboflavin) may be associated with PMS as low level of extracellular calcium and vitamin B complex cause swelling in lower extremities. The percentage of swollen extremities is $84.24 \%$ (mild $29.98 \%$, moderate $35.88 \%$, severe $18.38 \%$ and not effected $15.75 \%$ ). Abdominal bloating is another trouble in teenagers and majority of young ladies (90.6\%) felt distended stomach and a large number $(20 \%)$ suffered from extremely inflated belly while very little number (9.4\%) remains unaffected. Overall, the symptoms of PMS-H are statistically significant $(\mathrm{P}=0.0005)$ (Table 2). Before and during menstrual phase, females lurk upon spicy, fatty and caffeine rich diet (tea, coffee and caffeinated beverages) and this altered feeding habit may be the cause of abdominal distension and fluid retention. Alcohol worsens PMS symptoms and may increase the risk for prolonged cramping (dysmenorrhea) during menstruation [13]. Again the estrogen and progesterone is the main culprit behind the scene but woman's response to her own cyclical hormones is extremely individual, and this is part of the reason that it has been so difficult to pin down the causes of PMS. Estrogen levels that cause anxiety and bloating in one woman will have virtually no effect on another $[14,15]$. A woman who sails through an ovulatory cycle with hardly a ripple is in complete contrast to the woman who is plagued by migraines or anger premenstrually when she doesn't ovulate $[16,17]$.

\begin{tabular}{|l|l|l|l|l|l|l|}
\hline PMS Categories & Symptoms & Mild (\%) & Moderate (\%) & Sever (\%) & Not Effected (\%) & P value \\
\hline \multirow{2}{*}{ PMS-A } & Anxiety & 38.07 & 32.16 & 19.03 & 10.72 & 0.0006 \\
\cline { 2 - 7 } & Irritability & 28.66 & 30.4 & 21 & 20 & 16.2 \\
\cline { 2 - 7 } & Mood Swing & 33.5 & 28 & 22.32 & & \\
\hline
\end{tabular}


Citation: Mumtaz T, Roohi N, Iqbal MA (2018) A Census of Premenstrual Syndrome in Young Adolescent Girls: Facts about Women Health in Developing Country. Med Rep Case Stud 3: 159. doi:10.4172/2572-5130.1000159

Page 4 of 5

\begin{tabular}{|c|c|c|c|c|c|c|}
\hline & Nervous Tension & 34.8 & 28.5 & 17.5 & 19.25 & \\
\hline \multirow{5}{*}{ PMS-C } & Appetite increase & 33.48 & 18.81 & 7.44 & 40.27 & \multirow{5}{*}{$<0.0001$} \\
\hline & Headache & 28.88 & 22.97 & 12.91 & 35.22 & \\
\hline & Fatigue & 24.94 & 25.16 & 23.85 & 26.03 & \\
\hline & Dizziness & 26.48 & 22.53 & 16.84 & 34.13 & \\
\hline & Palpitation & 31.94 & 13.78 & 12.7 & 41.58 & \\
\hline \multirow{5}{*}{ PMS-D } & Depression & 34.8 & 19.5 & 14 & 31.72 & \multirow{5}{*}{$<0.0001$} \\
\hline & crying & 31.72 & 15.75 & 17.2 & 34.57 & \\
\hline & Forgetfulness & 28.22 & 15.53 & 8.75 & 47.48 & \\
\hline & confusion & 25.16 & 24.72 & 13 & 37.2 & \\
\hline & insomnia & 28.66 & 20.78 & 14.9 & 35.66 & \\
\hline \multirow{5}{*}{ PMS-H } & Fluid Retention & 27.13 & 34.13 & 26.03 & 12.7 & \multirow{5}{*}{0.0005} \\
\hline & Weight gain & 28.22 & 32.16 & 20.35 & 19.25 & \\
\hline & Swollen extremities & 29.98 & 35.88 & 18.38 & 15.75 & \\
\hline & Breast Tenderness & 33.26 & 30.63 & 21 & 14.66 & \\
\hline & Abdominal Bloating & 36.1 & 34.57 & 19.91 & 9.41 & \\
\hline
\end{tabular}

Table 2: Intensity percentages of PMS incidence.

\section{Implications for Practice and/or Policy}

Majority of young female population suffered from PMS but do not disclose due to social, religious and psychological pressure. It is time to educate our young generation about this disease because these physical, hormonal and psychological variations may cause severe reproductive health issues in future. Females must be able to recognize PMS and develop strategies to cope with it so that they avoid ragged and haphazard lifestyle. Behavioral abnormalities may also be prevented by timely management of the syndrome.

\section{Conclusion}

The survey is of preliminary type to govern the health status related to female reproductive cycle. The study is confined to one city of the country and figured out more than more than $92 \%$ young girls affected from PMS thus open the door for further assessment of women health of various ages. The study will encourage the health giving professionals and biostatisticians to pave more ways toward women health statistics.

\section{References}

1. Biggs WS, Demuth RH (2011) Premenstrual syndrome and premenstrual dysphoric disorder. Am Fam Physician 84: 918-924.

2. Braverman PK (2007) Premenstrual syndrome and premenstrual dysphoric disorder. J Pediatr Adolesc Gynecology 20: 3-12.

3. Chocano-Bedoya PO, Manson JE, Hankinson SE, Willett WC, Johnson SR et al. (2011) Dietary B vitamin intake and incident premenstrual syndrome. Am J Clin Nutr 93: 1080-1086.

4. Yonkers KA, O' Brien PMS, Eriksson E (2008) Premenstrual syndrome. Lancet 371: 1200-1210.
5. Shersha S, John JM, Sadiqa J (1991) Prevalence of premenstrual syndrome in Pakistani women. J Pak Med Assoc 41: 101-103.

6. Steiner M, Pearlstein T (2000) Premenstrual dysphoria and the serotonin system: pathophysiology and treatment. J Clin Psychiatry 61: 17-21.

7. Nisar N, Zehra N, Haider G, Munir AA, Sohoo NA (2008) Frequency, intensity and impact of premenstrual syndrome in medical students. J Coll Physicians Surg Pak 18: 481-484.

8. Henshaw CA, (2007) PMS: Diagnosis, aetiology, assessment and management: revisiting premenstrual syndrome. Adv Psychiatr Treat 13: 139-146.

9. Freeman EW, Halberstadt SM, Rickels K, Legler JM, Lin H, et al. (2011) Core symptoms that discriminate premenstrual syndrome. J Women's Health 20: 29-35.

10. Spinelli MG (2004) Depression and hormone therapy. Clin Obstetr Gyn 47: 428-436.

11. Meden-Vrtovec H, Vujic D (1992) Bromocriptine (Bromergon, Lek) in the management of premenstrual syndrome. Clin Exp Obstet Gynecol 19: 242-248.

12. Smith M, Segal R, Segal J (2014) Binge eating disorder: Symptoms, treatment, and help for compulsive overeating.

13. Arnedt JT, Rohsenow DJ, Almeida AB, Hunt SK, Gokhale M, et al. (2011) Sleep Following Alcohol Intoxication in Healthy, Young Adults: Effects of Sex and Family History of Alcoholism. Clin Exp Res 35: 870-878.a

14. American Psychiatric Association (1994) Diagnostic \& statistical manual of mental disorders. APA, Washington DC, US.

15. Bakhshani NM, Mousavi MN, Khodabandeh G (2009) Prevalence and severity of premenstrual symptoms among iranian female university students. J Pak Med Assoc 59: 205-208.

16. Brown J, O' Brien PM, Marjoribanks J, Wyatt K (2009) Selective serotonin reuptake inhibitors for premenstrual syndrome. Cochrane database of systematic reviews 2: CD001396. 
Citation: Mumtaz T, Roohi N, Iqbal MA (2018) A Census of Premenstrual Syndrome in Young Adolescent Girls: Facts about Women Health in Developing Country. Med Rep Case Stud 3: 159. doi:10.4172/2572-5130.1000159

Page 5 of 5

17. Jarvis CI, Lynch AM, Morin AK (2008) Management strategies for premenstrual syndrome/premenstrual dysphoric disorder. Ann Pharmacother 42: 967-978. 